\title{
PRÁTICA EXPERIMENTAL: EDUCAÇÃO AMBIENTAL, ENERGIA EÓLICA E O ENSINO DE FÍSICA
}

Claudemiro de Lima Júnior ${ }^{1}$

Fabricyo Villa Verde Silva ${ }^{2}$

Eduardo César de Miranda Loureiro ${ }^{3}$

Resumo: $O$ presente trabalho correlaciona o funcionamento das turbinas eólicas com assuntos da Física, abordando também a importância da utilização de fontes renováveis de energia. O papel fundamental da educação ambiental é reconhecido na conscientização da sociedade quanto à importância de usufruir dos recursos que a natureza oferece, sem prejudicá-la. Além disso, a educação torna-se mais efetiva quando os alunos reconhecem a importância do que se aprende em situações cotidianas. Encarregada dessa tarefa estão as práticas experimentais, principalmente, por se tratar de uma metodologia de ensino que permite aos professores ensinarem de forma mais conectada com o mundo e aos alunos aprenderem de forma mais efetiva e atrativa.

Palavras-chave: Metodologia de Ensino; Ciências Ambientais; Fontes Renováveis de Energia; Ciência da Natureza.

1Universidade de Pernambuco - E-mail: claudemiro.lima@upe.br

2 Instituto Federal Sertão Pernambucano - E-mail: fabricyo.villa@gmail.com

3 Universidade de Pernambuco - E-mail: eduloureiro@uol.com.br

Revbea, São Paulo, V. 14, № 3: 31-40, 2019.

revista brasileira educação ambiental 


\section{Introdução}

A energia está presente no universo de várias formas, sobretudo, todo processo físico envolve transferências ou transformações de energia (SERWAY; JEWETT, 2007, p.179). Diante da relevância desse tema nas ciências da natureza, torna-se inquestionável o papel unificador desse conceito na física, tão importante não somente do ponto de vista conceitual, mas também tecnológico (ASSIS; TEIXEIRA, 2003, p.41).

Além disso, é um dos principais constituintes da sociedade moderna, apresentando-se como fator determinante na desenvoltura econômica dos países e na qualidade de vida de seus habitantes (HINRICHS; KLEINBACH, 2000 , p.1). Por outro lado, na busca desenfreada pelo crescimento econômico, muitas vezes, os países fazem o planejamento da matriz energética sem se importar tanto com as limitações dos recursos, da mesma maneira com as consequências ambientais que possam surgir (LIMA JUNIOR, et al., 2018, p.234).

Diante de tais consequências, dentre elas, o desequilíbrio ambiental devido à exploração abusiva dos seus recursos, a educação ambiental apresenta-se como um movimento que pretende solucionar tais problemas. Dessa forma, manifesta-se como vertente que suscita a discussão dos valores básicos nos quais ela se apoia, oferecendo sugestões de retorno a valores mais humanos e da conquista de novos valores, em que se transcenda o antropocentrismo, alcançando uma nova síntese cultural e civilizatória na relação entre a sociedade e a natureza. (HAMMES et al., 2012, p.35).

Há muito tempo, o uso dos recursos naturais e as suas decorrentes questões ambientais são temas recorrentes no cenário político, econômico e nas pesquisas acadêmicas (SÁ; OLIVEIRA; NOVAES, 2015, p.61). Cada vez mais, torna-se necessário repensar sobre o uso das fontes de energia atuais, conscientizando a sociedade para o desenvolvimento sustentável, papel esse destinado à educação ambiental (PAULINO et al., 2017, p.140)

Nessa perspectiva, diante do cenário de preocupação com a emissão de gases do efeito estufa, principalmente, pelas mudanças causadas no aquecimento natural terrestre, as matrizes energéticas de muitos países contam, cada vez mais, com a participação mais constante de fontes renováveis de energia (CUSTÓDIO, 2007, p.7). Essas fontes, além de serem alternativas de produção energética que utilizam recursos que se renovam de forma natural e constante, também contribuem positivamente para o equilíbrio natural do planeta.

No Brasil, o potencial eólico para aproveitamento energético tem sido objeto de estudos desde os anos de 1970, mostrando-se com um potencial natural de relevante magnitude (AMARANTE, 2001, p.9). Basicamente, por se tratar da utilização da energia cinética contida nos ventos para produção de energia elétrica, compreender mais sobre o ciclo natural desse recurso torna-se fundamental quando se estuda o funcionamento da turbina eólica durante esse processo de conversão energética.

Revbea, São Paulo, V. 14, № 3: 31-40, 2019. 
Além do mais, a participação mais efetiva dessas fontes na matriz energética coopera para o desenvolvimento sustentável dos países. De acordo com as Nações Unidas, o conceito de desenvolvimento sustentável resume-se a "garantir as necessidades das gerações atuais, sem comprometimento às gerações futuras" (SILVA, 1996, p.32). Dessa forma, a educação ambiental surge com a perspectiva de produzir conhecimento a partir das relações socioambientais impostas pelo desenvolvimento, como dito anteriormente, voltada à sustentabilidade ambiental (JACOBI, 2003 apud NETTO, et al., 2017, p.25).

Desde o começo, a educação faz parte desse processo de construção de uma sociedade mais apta para resolver seus problemas e conviver harmonicamente, seja com a natureza, seja entre seus próprios cidadãos. $\mathrm{Da}$ mesma maneira, a prática experimental apresenta-se como metodologia que intensifica o desenvolvimento de indivíduos atuantes e críticos, competências tão necessárias no mundo atual. Além disso, permite que os alunos pesquisadores, durante todo o processo de aprendizagem, contextualizem todos os conceitos físicos, químicos, biológicos com a realidade que vivem, estimulando-os, cada vez mais, a aprender (OLIVEIRA, 2010, p.13).

Sendo assim, percebe-se que a educação ambiental constitui um processo de permanente aprendizagem, que busca desenvolver instrumentos pedagógicos efetivos para criar e aplicar formas sustentáveis de interação entre o homem e o meio ambiente (SÁ; OLIVEIRA; NOVAES, 2015, p.61). Por outro lado, as práticas experimentais apresentam-se como metodologia mais contextualizada com a realidade dos alunos. A partir dessas concepções, o presente trabalho apresenta uma metodologia, que permite correlacionar tais ideias, tratando-as como principais ferramentas para um processo de ensinoaprendizagem mais conectado com o que acontece no mundo.

Nesse contexto, apresenta-se um projeto realizado no Curso Superior de Engenharia, que culmina na montagem e teste de um pequeno protótipo experimental, envolvendo o funcionamento das turbinas eólicas. A princípio, abordando desde os conceitos físicos aplicados durante os processos de conversão energética, como também se utilizando do contexto de energias renováveis para debater a importância das relações socioambientais.

\section{Material e Métodos}

$\mathrm{Na}$ revisão bibliográfica, foram estudados alguns trabalhos que relacionavam a educação ambiental com o ensino das ciências da natureza, nesse caso, aos conceitos da física clássica. Segundo Batista et al. (2009, p.44, apud FREIRE, 1997), "para compreender a teoria, é preciso prová-la". Dessa forma, a metodologia desenvolvida consistiu-se na realização de um projeto de engenharia que englobava desde a criação, a montagem e testes de funcionamento dos protótipos em miniatura de cata-ventos construídos pelos alunos. Tornando-se possível estabelecer a dinâmica e indissociável relação 
entre a teoria e a prática em Física, bem como a importância ambiental dessas fontes na produção de energia.

Durante a prática, 0 professor intensifica a contextualização do experimento com a realidade, quando estimula o aluno a reconhecer o papel fundamental das fontes renováveis na obtenção de energia elétrica, além de correlacionar os assuntos da Física de forma mais atrativa. Como afirma Batista et al. (2009, p.46), "atributos com características essenciais à sedução do aprendiz para uma primeira aproximação podem ser encontrados no aparato experimental', correspondendo ao fascínio que o aparato pode oferecer, ao efeito interessante de determinado objeto ou à situação proposta no experimento.

Basicamente, na obtenção de energia elétrica por meio da energia contida nos ventos, ocorre a conversão da energia cinética de translação das massas de ar em energia cinética de rotação nas hélices da turbina eólica. Contextualizando com a Física, essa conversão energética foi relacionada com a dinâmica dos fluidos, nesse caso, ao movimento do ar com determinada velocidade na região delimitada pelas pás do aerogerador. Para que tais conceitos fossem explorados no experimento, foi proposto que a energia rotacional gerada nas pás deveria ser convertida em energia para erguer uma pequena massa ligada ao eixo principal do protótipo, conforme apresentado na Figura 1.

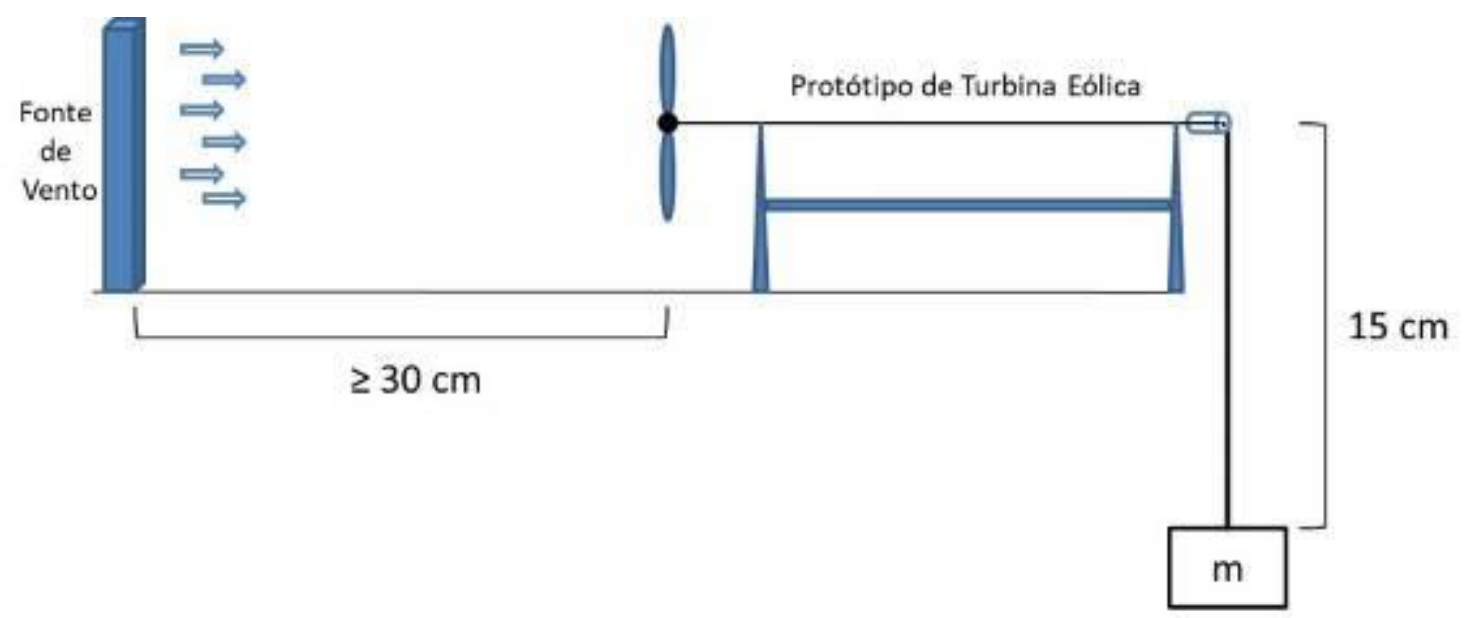

Figura 1: Montagem do Experimento.

Fonte: Os autores. 
Tabela 1: Lista de Materiais.

\begin{tabular}{|c|c|}
\hline Materiais Utilizados & $\begin{array}{c}\text { Contabilização } \\
\text { Sugerida }\end{array}$ \\
\hline Palito de Picolé & $\mathrm{R} \$ /$ Unidade \\
\hline Arame & $\mathrm{R} \$ /$ Metro \\
\hline Corda & $\mathrm{R} \$ /$ Metro \\
\hline Palito de Espetinho & $\mathrm{R} \$$ /Unidade \\
\hline Elástico & $\mathrm{R} \$ /$ Metro \\
\hline Palito de Dente & $\mathrm{R} \$ /$ Unidade \\
\hline Papel Alumínio & $\mathrm{R} \$$ Metro $^{2}$ \\
\hline Filme Plástico & $\mathrm{R} \$ /$ Metro $^{2}$ \\
\hline Fita Adesiva & $\mathrm{R} \$ /$ Metro \\
\hline Clipes de Papel & $\mathrm{R} \$ /$ Unidade \\
\hline Papelão & $\mathrm{R} \$ /$ Peça \\
\hline
\end{tabular}

Fonte: Os autores.

Com os protótipos construídos, em data predeterminada, foram realizados os testes de desempenho, debatendo-se também sobre os conceitos físicos e implicações ambientais envolvidas no projeto. Dentre os quais, mostrou-se que a energia cinética dos ventos $(E)$ é utilizada para geração de energia elétrica nas turbinas, e o fluxo de ar com massa $(m)$ se desloca com determinada velocidade $(v)$, como apresentado na Equação 1.

$$
E=\frac{1}{2} m v^{2} \quad \text { Equação } 1
$$

Considerando a geometria constituída por um cilindro de área transversal $(A)$ e comprimento $(d)$, apresentada na Figura 2, a qual representa o movimento das massas de ar numa região específica do espaço. 


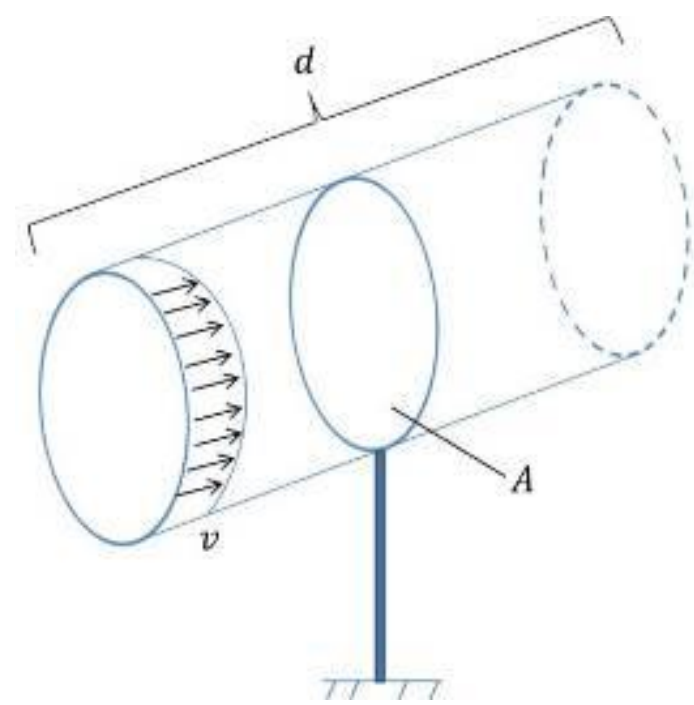

Figura 2: Geometria do Movimento das Massas de Ar.

Fonte: Os autores.

O volume $(V)$ dessa geometria vai ser o produto entre a área transversal $(A)$ e o comprimento $(d)$. Sabendo que esse tubo cilíndrico é percorrido por um fluido com velocidade $(v)$ num instante de tempo $(t)$, o volume contido na geometria será o produto entre a área transversal, a velocidade e o tempo decorrido para atravessar todo o cilindro, Equação 2. (PICOLO, A. P. et al., 2014, p.7).

$$
V=A \cdot d=A \cdot v \cdot t \quad \text { Equação } 2
$$

A vazão $(Q)$ do fluido é a taxa de variação temporal do volume $(V)$ do fluido, que atravessa a geometria de área transversal $(A)$ e comprimento $(d)$, conforme a Equação 3.

$$
Q=\frac{d V}{d t}=A \cdot v
$$

Equação 3

$\mathrm{Na}$ hidrodinâmica, em um regime de escoamento permanente e incompressível, o fluxo de massa que atravessa a geometria pode ser determinado da seguinte forma, Equação 4, onde (ø) é o fluxo de massa e $(\rho)$ é a massa específica do ar. (SERWAY, R. A.; JEWETT, J. W., 2007, p.107).

$$
\varnothing=\frac{d m}{d t}=\rho \cdot v \cdot A \quad \text { Equação } 4
$$

Revbea, São Paulo, V. 14, № 3: 31-40, 2019. 
Sabendo que, $\rho=\frac{m}{V}$, a energia cinética $(E)$ pode ser reescrita, da seguinte forma, Equação 5 .

$$
E=\frac{1}{2} m v^{2}=\frac{1}{2} \rho \cdot V \cdot v^{2}=\frac{1}{2} \rho \cdot A \cdot v \cdot t \cdot v^{2}=\frac{1}{2} \rho \cdot A \cdot v^{3} \cdot t \quad \text { Equação } 5
$$

A potência é a taxa de variação temporal da energia e, portanto, derivando a equação em relação ao tempo, pode-se determinar a potência eólica $\left.{ }^{P}\right)$ disponível no vento que passa por uma secção transversal de área $\left.{ }^{(}\right)$, como na Equação 6 , onde $\left({ }^{P}\right)$ é a potência do vento, $\left({ }^{A}\right)$ é a área varrida pelas pás em movimento da turbina eólica e $\left(^{v}\right)$ é a velocidade do vento. (PICOLO, A. P. et al., 2014, p.7).

$$
P=\frac{d E}{d t}=\frac{1}{2} \rho \cdot A \cdot v^{3} \quad \text { Equação } 6
$$

A partir da Equação 6, pode-se constatar que a potência disponível é proporcional ao cubo da velocidade do vento. Essa informação nos revela que a potência é fortemente dependente dessa velocidade; por isso, para a utilização da energia eólica é necessário que haja um fluxo constante e razoavelmente forte de vento.

Diante da dificuldade de medir a velocidade do vento propulsor dos pequenos protótipos, foi proposta uma forma alternativa de medir essa grandeza. Mantendo-se o posicionamento apresentado na Figura 1, cronometrou-se o tempo necessário para levantar a massa padrão, duas moedas de $\mathrm{R} \$ 0,50$, a uma altura de quinze centímetros. Posteriormente, para o cálculo da eficiência, relacionaram-se os valores dos materiais utilizados na construção com o tempo cronometrado para cada protótipo por meio da Equação 7.

$$
\text { Eficiência }=\frac{1}{(\text { Custo dos Materiais)(Tempo para levantar a massa })} \quad \text { Equação } 7
$$

\section{Resultados e Discussão}

Durante as apresentações, foram promovidos debates sobre a importância ambiental das fontes renováveis na obtenção de energia, como também dos conceitos físicos, citados na secção anterior, envolvidos no funcionamento das turbinas eólicas. Na Figura 3, os protótipos construídos por 
cada equipe, cada um com uma determinada configuração, principalmente no formato e tamanho das pás, nesse caso, influenciando a potência eólica do protótipo, conforme a Equação 6.

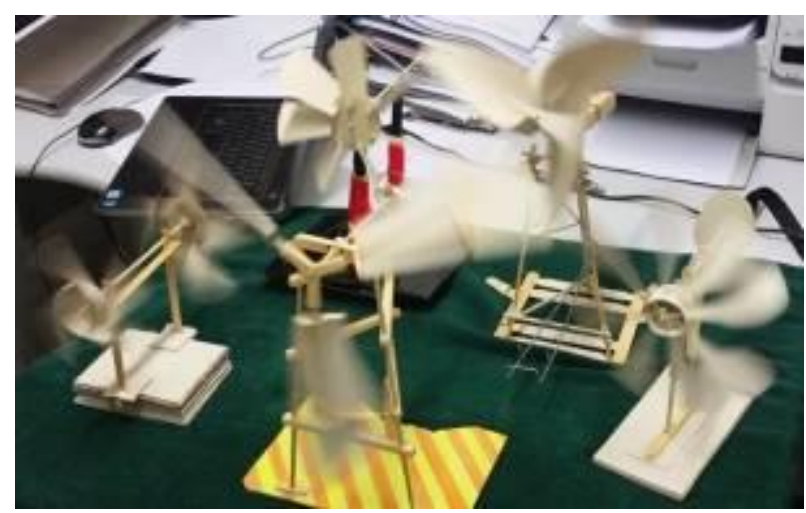

Figura 3: Modelos de Cata-Ventos.

Fonte: Os autores.

$\mathrm{Na}$ Figura 4, um dos protótipos, utilizando a potência eólica disponibilizada para erguer a massa a uma determinada altura do eixo principal do cata-vento. As condições de funcionamento dos modelos dependem principalmente das condições de vento, e dos materiais utilizados e da simetria de toda a estrutura montada.

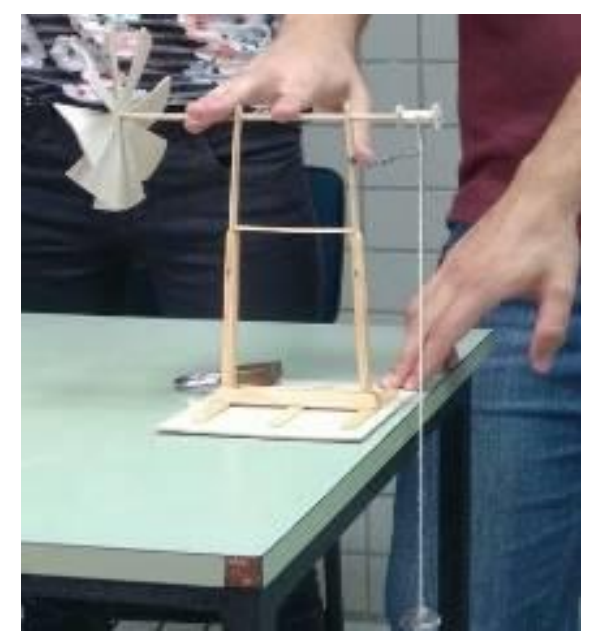

Figura 4: Protótipo com Massa Padrão.

Fonte: Os autores.

No cálculo da eficiência dos protótipos, a área compreendida pelas pás tem forte influência sobre o processo de conversão da energia cinética contida nos ventos em energia mecânica rotacional das pás. Nesse contexto, além de serem elaborados e construídos com distintos materiais, pelo fato de os protótipos possuírem formatos, tamanhos e quantidades de pás distintos, a eficiência no processo de conversão de energia será característico de cada modelo.

Revbea, São Paulo, V. 14, № 3: 31-40, 2019. 


\section{Conclusões}

Apresentou-se uma metodologia de ensino, que retrata a importância da prática experimental em sala de aula, como ferramenta essencial na associação da teoria com a prática, principalmente, por incentivar o estudante a entender situações cotidianas com o que foi aprendido nas aulas. A educação é imprescindível na formação intelectual de todo e qualquer indivíduo, como também na sua formação cidadã. Sabendo disso, a educação ambiental tem papel fundamental em conscientizar a sociedade de preservar 0 meio ambiente.

Nesse contexto, debater em sala de aula as novidades tecnológicas em termos de obtenção de energia, propicia aos alunos compreender um pouco mais sobre o funcionamento delas e os benefícios e malefícios, que trazem à natureza. Sendo assim, a metodologia desenvolvida englobou todos esses aspectos, seja a educação ambiental, relacionando a importância de usufruir dos recursos naturais cautelosamente, preservando a natureza. Como também, compreendendo a Física no funcionamento das turbinas eólicas de uma forma bastante atrativa, através do experimento, podendo, assim, funcionar como um estímulo tanto para os alunos, como para o professor em relação ao estudo da Física e da educação ambiental, aprendizados tão importantes para compreender tudo aquilo que acontece no meio em que vive.

\section{Agradecimentos}

Os autores agradecem o apoio financeiro da Fundação de Amparo à Ciência e Tecnologia do Estado de Pernambuco - FACEPE, pela concessão da bolsa de iniciação científica (BIC-2496-1.05/16). O presente trabalho foi realizado com o apoio da Coordenação de Aperfeiçoamento de Pessoal de Nível Superior -Brasil (CAPES) - Código de Financiamento 001 ao Programa de Pós-Graduação em Ciência e Tecnologia Ambiental para o Semiárido da Universidade de Pernambuco.

\section{Referências}

AMARANTE, O.A.C. et al. Atlas do Potencial Eólico Brasileiro. Brasília: CRESESB, 2001.

ASSIS, A.; TEIXEIRA, O.P.B. Algumas considerações sobre o ensino e a aprendizagem do conceito de energia. Ciência e Educação, Bauru, v. 9, n. 1, p. 41-52, 2003.

BATISTA, M.C. FUSINATO, P.A. BLINI, R.B. Reflexões sobre a importância da experimentação no ensino. Acta Scientiarum. Human and Social Sciences 31.1 (2009): 43-49.

CUSTÓDIO, R.S. Energia Eólica - Para Produção de Energia Eólica. Rio de Janeiro: Eletrobrás, 2009. 
HAMMES, V.S. et al. Construção da proposta pedagógica. 3. ed. rev. e ampl. Brasília: EMBRAPA, 2012. v.1 - Educação Ambiental para o desenvolvimento sustentável, $394 \mathrm{p}$.

HINRICHS, R.; KLEINBACH, M. Energia e Meio Ambiente. Thomson, 2000.

LIMA JUNIOR, C. et al. Energia Solar: metodologia para avaliação do local de instalação de sistema fotovoltaico fomentando a educação ambiental. Revbea, São Paulo, v.13, n.3, p.233 - 244, 2018.

NETTO, T.A. et al. A educação como meio de transformação social: o projeto arquitetos do saber. Revbea. São Paulo, v.12, n. 2, p.23-33, 2017.

OLIVEIRA, M.M.L. O papel da experimentação no ensino pela pesquisa em física. Dissertação (Mestrado em Educação em Ciências e Matemática). 198p. Porto Alegre. PUCRS, 2010.

PAULINO, T.F.; PINTO, M.S.; COSTA, G.V.; BAMBIRRA, M.B.; PAULINO, E. S. Oficinas educacionais: atividade de extensão como método para a melhor utilização da energia para estudantes do ensino fundamental. Revista Brasileira de Educação Ambiental. São Paulo, v.11, n. 5, p. 139 - 151, 2017.

PICOLO, A.P. et al. Uma abordagem sobre a energia eólica como alternativa de ensino de tópicos de física clássica. Revista brasileira de ensino de física, v. 36, n. 4, 4306, 2014.

SÁ, M.A.; OLIVEIRA, M.A.; NOVAES, A.S.R. A importância da educação ambiental para o ensino médio. Revista Brasileira de Educação Ambiental. São Paulo, v. 10, n. 3, p. 60-68, 2015.

SERWAY, R.A.; JEWETT, J.W. Princípios de Física. 3. ed. São Paulo: Thomson Learning, 2007. v.1 - Mecânica Clássica, 403 p.

SERWAY, R.A.; JEWETT, J.W. Princípios de Física. 3. ed. São Paulo: Thomson Learning, 2007. v.2 - Oscilações, Ondas e Termodinâmica, 403 p.

SILVA, D.J. Viva a floresta viva. Florianópolis: Secretaria de Estado de Desenvolvimento Urbano e Meio Ambiente-Programa de Educação Ambiental, 1996, p.96. 